\title{
PELATIHAN PENGEMBANGAN MANAJEMEN PEMBELAJARAN UNTUK MENGHADAPAI MASYARAKAT EKONOMI ASEAN (MEA) MELALUI LESSON STUDI BASED LEARNING COMMUNITY DI SMP/MTS SE-KABUPATEN BANTUL
}

\author{
Oleh: \\ Yahya Hanafi, Nani Aprilia \\ Universitas Ahmad Dahlan Yogyakarta \\ E-mail: yahya.hanafi@pbio.uad.ac.id
}

\section{Ringkasan}

Pendidikan memegang peran yang sangat penting dalam proses peningkatan kualitas sumber daya manusia. Peningkatan kualitas pendidikan merupakan suatu proses yang terintegrasi dengan proses peningkatan kualitas sumber daya manusia itu sendiri. Peningkatan kualitas, kapasitas, kompetensi pedagogik-profesional dan pembinaan profesi pendidik (dalam hal ini guru) khususnya di Amal Usaha Muhammadiyahn (AUM) Sekolah Kabupaten Bantul (SMP/MTs) dapat dilakukan melalui melalui kegiatan Lesson study. Lesson study merupakan kegiatan yang dapat mendorong terbentuknya sebuah komunitas belajar (learning society) yang secara konsisten dan sistematis melakukan perbaikan diri, baik pada tataran individual maupun manajerial. Tahapan-tahapan dalam lesson study menggunakan konsep Plan-Do-Check-Act (PDCA). Kegiatan pelatihan lesson study diselenggarakan pada tanggal 10, 14, dan 16 Agustus 2017 di Kantor Pimpinan Daerah Muhammadiyah Kabupaten Bantul, dengan peserta perwakilan guru SMP/MTs Muhammadiyah seKabupaten Bantul. Output kegiatan pelatihan yaitu terbentuknya komunitas lesson study di SMP/MTs Muhammadiyah se-Kabupaten Bantul. Tindak lanjut kegiatan yaitu penerapan lesson study di masing-masing sekolah, dengan cara pelaksanaan berbasis MGMP, berbasis sekolah, dan berbasis komunitas.

Kata kunci: Lesson Study, Komunitas, Guru, Sekolah, Kompetensi

\begin{abstract}
Education plays a very important role in the process of improving the quality of human resources. Improving the quality of education is a process that is integrated with the process of improving the quality of human resources itself. Improved quality, capacity, pedagogicalprofessional competence and professional development of teachers (in this case teachers) especially in Muhammadiyahn Business Amal (AUM) Bantul District School (SMP) MTs) can be done through through Lesson study activities. Lesson study is an activity that can encourage the formation of a learning community (learning society) that consistently and systematically perform selfimprovement, both at individual and managerial level. The stages in the lesson study use the PlanDo-Check-Act (PDCA) concept. Lesson study training activities were held on 10th, 14th and 16th of August 2017 at Muhammadiyah Regional Office of Bantul District, with representatives of junior high school teachers / MTs Muhammadiyah in Bantul District. Output of training activities is the formation of community lesson study in SMP / MTs Muhammadiyah in Bantul District. Follow-up activities are the application of lesson study in each school, by way of MGMP-based, school-based, and community-based implementation.
\end{abstract}

Keywords: Lesson Study, Community, Teacher, School, Competency 


\section{A. PENDAHULUAN}

Perkembangan ilmu pengetahuan dan teknologi telah membawa perubahan di hampir semua aspek kehidupan manusia dimana berbagai permasalahan hanya dapat dipecahkan kecuali dengan upaya penguasaan dan peningkatan ilmu pengetahuan dan teknologi. Agar mampu berperan dalam persaingan global, maka sebagai bangsa kita perlu terus mengembangkan dan meningkatkan kualitas sumber daya manusianya. Ada beberapa kekuatan yang akan mengubah perjalanan hidup kita tentang cara belajar (Learning Revolution) sebagaimana digambarkan Dryen (2000) dalam Siti Irene Astuti (2003) bahwa dunia sedang bergerak sangat cepat melalui titik balik sejarah yang menentukan. Oleh karena itu, peningkatan kualitas sumber daya manusia merupakan kenyataan yang harus dilakukan secara terencana, terarah, intensif, efektif dan efisien dalam proses pembangunan, kalau tidak ingin bangsa ini kalah bersaing dalam menjalani era globalisasi tersebut. Berkaitan dengan kualitas sumber daya manusia, pendidikan memegang peran yang sangat penting dalam proses peningkatan kualitas sumber daya manusia. Peningkatan kualitas pendidikan merupakan suatu proses yang terintegrasi dengan proses peningkatan kualitas sumber daya manusia itu sendiri. Menyadari pentingnya proses peningkatan kualitas sumber daya manusia, maka pemerintah bersama kalangan swasta sama-sama telah dan terus berupaya mewujudkan amanat tersebut melalui berbagai usaha pembangunan pendidikan yang lebih berkualitas antara lain melalui pengembangan dan perbaikan kurikulum dan sistem evaluasi, perbaikan sarana pendidikan, pengembangan dan pengadaan materi ajar, serta pelatihan bagi guru dan tenaga kependidikan lainnya. (Umaedi, 2004).

Pembelajaran merupakan jantung dari proses pendidikan dalam suatu institusi Pendidikan. Kualitas pembelajaran bersifat kompleks dan dinamis, dapat dipandang dari berbagai persepsi dan sudut pandang melintasi garis waktu. Pada tingkat mikro, pencapaian kualitas pembelajaran merupakan tanggung jawab profesional seorang dosen atau guru, misalnya melalui penciptaan pengalaman belajar yang bermakna bagi siswa dan fasilitas yang didapat siswa untuk mencapai hasil belajar yang maksimal. Pada tingkat makro, melalui sistem pembelajaran yang berkualitas, lembaga pendidikan bertanggung jawab terhadap pembentukan tenaga pengajar yang berkualitas, yaitu yang dapat berkontribusi terhadap perkembangan intelektual, sikap, dan moral dari setiap individu peserta didik sebagai anggota masyarakat.

Faktor-faktor yang berpengaruh terhadap proses baik secara eksternal maupun internal diidentifikasikan sebagai berikut. Faktor-faktor eksternal mencakup guru, materi, pola interaksi, media dan teknologi, situasi belajar, dan sistem. Masih ada pendidik/guru yang kurang menguasai materi dan dalam mengevaluasi mahasiswa menuntut jawaban yang persis seperti yang ia jelaskan; dengan kata lain, siswa tidak diberi peluang untuk berfikir kreatif. Guru juga mempunyai keterbatasan

dalam mengakses informasi baru yang memungkinkan ia mengetahui perkembangan terakhir di bidangnya (state of the art) dan kemungkinan perkembangan yang lebih jauh dari yang sudah dicapai sekarang (frontier of knowledge). Sementara itu materi pembelajaran dipandang oleh siswa terlalu teoritis, kurang memberi contoh-contoh yang 
Diterbitkan oleh Lembaga Pengabdian kepada Masyarakat

Universitas Ahmad Dahlan Yogyakarta

kontekstual. Metode penyampaian bersifat monoton, kurang memanfaatkan berbagai media secara optimal (DIKTI, 2004).

Berdasarkan penjelaskan di atas, terdapat hal-hal yang perlu diperhatikan oleh lembaga pendidikan dimana dituntut untuk terus berusaha meningkatkan kualitas pembelajaran dan proses penyelenggaraan pendidikan, sehingga perlu dicari strategi pencapaian kualitas pembelajaran di lembaga pendidikan. Strategi pembelajaran yang dimaksudkan adalah pendekatan atau taktik secara keseluruhan yang berkaitan dengan pelaksanaan gagasan, perencanaan, dan eksekusi sebuah aktivitas dalam kurun waktu tertentu yang berkaitan dengan pembelajaran. Strategi yang ditawarkan sebagai pembentukan manajemen pembelajaran adalah dengan menggunakan Lesson study. Lesson study adalah suatu model pembinaan profesi pendidik melalui pengkajian pembelajaran kolaboratif dan berkelanjutan berlandaskan prinsip-prinsip kolegalitas dan mutual learning untuk membangun komunitas belajar (Sumar Hendayana, dkk: 2006). Lesson study merupakan pendekatan yang komprehensif menuju pembelajaran yang profesional serta menopang guru menjadi pembelajar sepanjang hayat dalam upaya mengembangkan dan meningkatkan kualitas pembelajaran di kelas. Lesson study bukan merupakan suatu metode atau strategi pebelajaran tetapi kegiatan lesson study dapat menerapkan berbagai metode atau strategi pembelajaran yang sesuai dengan situasi, kondisi, dan permasalahan yang dihadapi guru.

Berdasarkan uraian diatas maka perlu dilakukan peningkatan kualitas, kapasitas, kompetensi dan pembinaan profesi pendidik (dalam hal ini guru) khususnya di AUM Sekolah Kabupaten Bantul (SMP/MTs). Salah satu cara yang dapat digunakan untuk meningkatkan kualitas, kapasitas, kompetensi dan pembinaan profesi pendidik yaitu melalui Lesson study. Setelah mengikuti kegiatan pelatihan Lesson study diharapkan dapat meningkatkan kompetensi guru, khususnya kompetensi pedagogik dan kompentensi profesional. Sasaran kegiatan pelatihan yaitu guru-guru SMP/MTs Muhammadiyah seKabupaten Bantul untuk mata pelajaran IPA khususnya, dan mata pelajaran lain pada umumnya.

\section{B. METODE PELAKSANAAN}

Dalam pelaksanaan pelatihan digunakan beberapa metode agar selama proses pelatihan peserta lebih memahami materi dan hasilnya sesuai dengan yang diharapkan. Sebagaimana pengertian dari metode adalah alat yang efektif untuk mencapai tujuan, baik berupa goal oriented atau goal free dari sebuah program yang telah dirancang. Dalam pelatihan ini metode yang digunakan yaitu ceramah, demonstrasi, diskusi, dan praktik. Kegiatan pelatihan dilaksanakan pada tanggal 10,14 dan 16 Agustus 2017 di Kantor Pimpinan Daerah Muhammadiyah Kabupaten Bantul, diikuti oleh perwakilan guru SMP/MTs Muhammadiyah se-Kabupaten Bantul. 
Tabel 1. Materi pelatihan

\begin{tabular}{|c|c|c|}
\hline NO. & MATERI & JKEM \\
\hline 1. & Konsep Lesson study learning community & 3 \\
\hline 2. & $\begin{array}{l}\text { Pengarahan tentang Observasi pembelajaran (etika pada saat } \\
\text { observasi) }\end{array}$ & 3 \\
\hline 3. & Pembelajaran kolaboratif untuk mendukung LSLC & 3 \\
\hline 4. & Lesson design dalam LSLC & 4 \\
\hline 5. & Diskusi Kelompok & 3 \\
\hline 6. & $\begin{array}{l}\text { Peranan peneliti : membantu sekolah dan pemerintah serta } \\
\text { trend pengkajian LS }\end{array}$ & 4 \\
\hline 7. & $\begin{array}{l}\text { Teknik pengambilan video dan menganalisis video } \\
\text { pembelajaran }\end{array}$ & 3 \\
\hline 8. & Teknik editing video dalam pembelajaran (Joint Curter) & 2 \\
\hline 9. & Praktik Pengambilan video dan editing video & 3 \\
\hline 10 . & $\begin{array}{l}\text { Kebijakan dan strategi Dikdasmen PDM Bantul untuk } \\
\text { meningkatkan kualitas, kapasitas, dan kompetensi guru } \\
\text { menghadapi Masyarakat Ekonomi Asean (MEA) }\end{array}$ & 2 \\
\hline 11. & Rencana Tindak Lanjut (RTL) & 1 \\
\hline
\end{tabular}

\section{HASIL, PEMBAHASAN DAN DAMPAK}

Pembelajaran adalah upaya sistematis dan sistemik untuk menginisiasi, memfasilitasi dan meningkatkan proses belajar, oleh karena kegiatan pembelajaran sangat berkaitan erat dengan jenis hakikat serta jenis belajar dan prestasi belajar tersebut. Konsep dan praktik Lesson Study pertama kali dikembangkan oleh para guru pendidikan dasar di Jepang, yang dalam bahasa Jepang-nya disebut dengan istilah kenkyuu jugyo. Lesson Study dikembangkan pada pendidikan dasar, namun saat ini ada kecenderungan untuk diterapkan pula pada pendidikan menengah dan bahkan pendidikan tinggi. Lesson Study bukanlah suatu strategi atau metode dalam pembelajaran, tetapi merupakan salah satu upaya pembinaan untuk meningkatkan proses pembelajaran yang dilakukan oleh sekelompok guru secara kolaboratif dan berkesinambungan, dalam merencanakan, melaksanakan, mengobservasi dan melaporkan hasil pembelajaran.

Lesson Study merupakan kegiatan yang dapat mendorong terbentuknya sebuah komunitas belajar (learning society) yang secara konsisten dan sistematis melakukan perbaikan diri, baik pada tataran individual maupun manajerial. Berkenaan dengan tahapan-tahapan dalam Lesson Study ini, dijumpai beberapa pendapat. Menurut Sumar, H (2006) bahwa Lesson Study dilakukan melalui empat tahapan dengan menggunakan konsep Plan-Do-Check-Act (PDCA). Lesson study adalah suatu model pembinaan profesi pendidik melalui pengkajian pembelajaran kolaboratif dan berkelanjutan berlandaskan prinsipprinsip kolegalitas dan mutual learning untuk membangun komunitas belajar (Sumar Hendayana, dkk: 2006). Lesson study merupakan pendekatan yang komprehensif menuju pembelajaran yang profesional serta menopang guru menjadi pembelajar sepanjang hayat 
Diterbitkan oleh Lembaga Pengabdian kepada Masyarakat

Universitas Ahmad Dahlan Yogyakarta

dalam upaya mengembangkan dan meningkatkan kualitas pembelajaran di kelas. Lesson study bukan merupakan suatu metode atau strategi pebelajaran tetapi kegiatan lesson study dapat menerapkan berbagai metode atau strategi pembelajaran yang sesuai dengan situasi, kondisi, dan permasalahan yang dihadapi guru.

Peserta kegiatan pelatihan yaitu guru-guru SMP/MTs Muhammadiyah seKabupaten Bantul. Kegiatan diselenggarakan di Gedung Dakwah Muhammadiyah Bantul pada tanggal 10,14, dan 16 Agustus 2017. Manfaat yang diperoleh peserta pelatihan yaitu : mengurangi keterasingan guru (dari komunitasnya), khususnya dalam pembelajaran, meningkatkan akuntabilitas kinerja guru, membantu guru untuk mengobservasi dan mengkritisi pembelajarannya, memperdalam pemahaman guru tentang materi pelajaran, cakupan dan urutan materi dalam kurikulum, membantu guru memfokuskan bantuannya pada seluruh aktivitas belajar siswa, menciptakan terjadinya pertukaran pengetahuan para guru tentang pemahaman berpikir dan belajar siswa, meningkatkan kolaborasi pada sesama guru, meningkatkan kompetensi, kualitas, dan kapasitas guru SMP/MTs Muhammadiyah se-Kabupaten Bantul; membantu mencapai pembelajaran yang menyenangkan dan bermutu; meningkatkan kompetensi pedagogik dan profesional guru.

Lesson study perlu dilakukan karena beberapa alasan yaitu : pengembangan lesson study dilakukan dan didasarkan pada hasil "sharing" pengetahuan profesional yang mempertimbangkan pada praktik dan hasil pembelajaran yang dilaksanakan para guru, penekanan dari lesson study adalah bagaimana para siswa memiliki kualitas belajar yang tinggi, pengembangan kompetensi siswa dijadikan fokus dan titik perhatian utama dalam implementasi lesson study, pengembangan lesson study dilakukan dan didasarkan pada hasil "sharing" pengetahuan profesional yang mempertimbangkan pada praktik dan hasil pembelajaran yang dilaksanakan para guru, penekanan dari lesson study adalah bagaimana para siswa memiliki kualitas belajar yang tinggi, pengembangan kompetensi siswa dijadikan fokus dan titik perhatian utama dalam implementasi lesson study, membantu guru dalam mengobservasi dan mengkritisi (refleksi diri) pembelajaran yang dilakukannya, memperdalam pemahaman guru tentang materi pelajaran, cakupan dan urutan materi dalam kurikulum, menciptakan terjadinya pertukaran pengetahuan para guru tentang pemahaman cara berpikir dan belajar siswa, menumbuhkan sikap keterbukaan di antara sesama kolega guru, Menumbuhkan rasa percaya diri yang tinggi pada guru, dapat menjadi alat evaluasi terhadap kelebihan dan kekurangan yang dimiliki guru, dapat merangsang keinginan untuk membuat karya ilmiah (Action Research) dan buku ajar, ajang pemilihan berbagai metode pembelajaran yang relevan dengan kemampuan siswa.

Dampak dari penyelenggaraan lesson study yaitu : peningkatan mutu guru dan mutu pembelajaran yang pada gilirannya berakibat pada peningkatan mutu lulusan (siswa), guru memiliki banyak kesempatan untuk membuat bermakna ide-ide pendidikan dalam praktik pembelajarannya sehingga dapat merubah perspektif tentang pembelajaran, dan belajar praktik pembelajaran dari perspektif siswa, guru mudah berkonsultasi dengan akrab kepada pakar dalam hal pembelajaran atau kesulitan materi pelajaran, perbaikan praktik pembelajaran di kelas, peningkatan kolaborasi antar guru dan antara guru dan pakar/guru dalam meningkatkan kualitas pembelajaran, peningkatan ketrampilan menulis karya tulis ilmiah atau buku ajar. 
Output dari kegiatan pelatihan yaitu terbentuknya komunitas lesson study di SMP/MTs Muhammadiyah se-kabupaten Bantul sehingga dapat melakukan tindak lanjut pelatihan dengan menerapkan lesson study pada masing-masing sekolah. Langkah-langkah pelaksanaan lesson study yaitu: membentuk kelompok lesson study, memfokuskan lesson study, menyusun rencana pelaksanaan pembelajaran (RPP) dan perangkat lainnya, melaksanakan pembelajaran di kelas dan mengamatinya (observasi), refleksi dan menganalisis pembelajaran yang telah dilaksanakan, merencanakan pembelajaran tahap selanjutnya. Pelaksanaan lesson study dapat dilakukan dengan cara berbasis MGPM, berbasis sekolah, dan berbasis komunitas.

\section{KESIMPULAN}

Lesson Study merupakan kegiatan yang dapat mendorong terbentuknya sebuah komunitas belajar (learning society) yang secara konsisten dan sistematis melakukan perbaikan diri, baik pada tataran individual maupun manajerial. Tahapan-tahapan dalam Lesson Study menggunakan konsep Plan-Do-Check-Act (PDCA). Materi yang disampaikan meliputi : Sosialisasi lesson study based learning community dan lesson study based mata pelajaran; pengembangan lesson design dan model cooperative learning; pengembangan observasi pembelajaran kelas, editing, analisis dan praktik video pembelajaran. Output kegiatan pelatihan yaitu terbentuknya komunitas lesson study di SMP/MTs Muhammadiyah se- Kabupaten Bantul. Tindak lanjut kegiatan yaitu penerapan lesson study di masing- masing sekolah, dengan cara berbasis MGMP, berbasis sekolah, dan berbasis komunitas.

\section{DAFTAR PUSTAKA}

Aqib, Zainal. 2013. Model-model, Media, dan Strategi Pembelajaran Kontekstual (Inovatif). Bandung: Yrama Widya.

Departemen Pendidikan Nasional Direktorat Jenderal Pendidikan Tinggi Direktorat Pembinaan Pendidikan Tenaga Kependidikan dan Ketenagaan Perguruan Tinggi, (2004); Peningkatan Kualitas Pembelajaran. Jakarta

Djemari Mardapi. (1996); Implementasi Pola Ilmiah Pokok Pendidikan Berwawasan Budaya pada Proses Pembelajaran. Makalah Semiloka Sosialisasi Rambu-rambu Implementasi PIP Pendidikan Berwawasan Budaya. IKIP Yogyakarta. 31 Desember 1996.

Lewis, Catherine C. 2002. Lesson Study:A Handbook of Teacher-Led Instructional Change. Philadelphia, PA: Research for Better Schools. Inc.

M. Zainudin dan Susy Puspitasari; (2001); Strategi Peningkatan Kualitas Pendidikan Tinggi I; PAU untuk Peningkatan Pengembangan Aktivitas Instruksiional Dirjen Dikti, Departemen Pendidikan Nasional. Jakarta

Sagala, Syaiful. 2012. Konsep dan Makna Pembelajaran. Bandung: Alfabeta.

Suyono dan Hariyanto. 2011. Belajar dan Pembelajaran Teori dan Konsep Dasar. Surabaya: Rosda. 
Diterbitkan oleh Lembaga Pengabdian kepada Masyarakat

Universitas Ahmad Dahlan Yogyakarta

Siti Irene Astuti D (2003); Pengembangan Kecakapan Hidup (Life Skill) Melalui Penanaman Etos Kerja dan Membangun Kreativitas Anak. Cakrawala

Pendidikan Jurnal Ilmiah Pendidikan; Lembaga Pengabdian Kepada Masyarakat; Universitas Negeri Yogyakarta.

Sumar Hendayana, dkk. 2006. Lesson Study. Suatu Strategi untuk Meningkatkan Keprofesionalan Pendidik. UPI Press.

Udin S. Winataputra. 2007. Teori Belajar dan Pembelajaran. Jakarta: Universitas Terbuka.

Vygotsky, L.S. 1978. Mind in society: the development of higher psychological Processes. Cambridge, MA: Havard University Press. 
